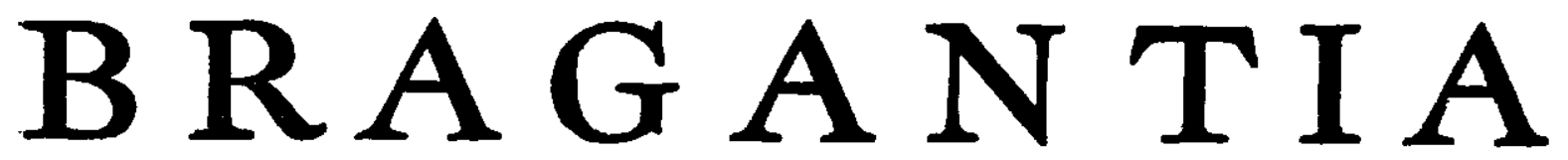

Boletim Técnico da Divisão de Experimentação e Pesquisas IN STITUTOAGRONÔMICO

Vol. 7 Campinas, Novembro-Dezembro de $1947 \quad \mathrm{~N}^{\text {as }} 11-12$

\title{
ESTUDO AGRÍCOLA-TECNOLÓGICO DE DIVERSAS VARIEDADES DE PHORMIUM TENAX FORSTER
}

J. C. Medina

J. M. Aguirre Júnior

F. A. Correia

\section{I - INTRODUÇÃO}

O gênero Phormium, fornecedor da fibra conhecida nos mercados pelos nomes de cânhamo ou linho da Nova Zelândia, ou, simplesmente, por fórmio, pertence à família Liliacex, e tem como centro de origem a Nova Zelândia -e ilhas adjacentes, onde vegeta espontâneamente sob diversas situações, desde as várzeas pantanosas até encostas dos morros, em altitudes variando do nível do mar até 1.200 metros.

Admite-se, em geral, que o gênero compreende as duas espécies seguintes : $P$. tenax Forster, a espécie típica do gênero e explorada comercialmente, e $P$. Cookianum Le Jolis ( $P$. Colensoi Hooker), de distribuição geográfica mais restrita (endêmico só na Nova Zelândia) e, até o presente, de pouco valor comercial como planta téxtil.

Sabe-se, desde há muito tempo, que a espécie $P$. tenax apresenta um acentuado polimorfismo, principalmente no grau de rigidez das fôlhas, caráter geralmente utilizado para distinguir as diversas formas ou variedades.

Allan e Zotov (1) relatam que o grande polimorfismo da planta já era conhecido pelos nativos da Nova Zelândia, que cultivavam diversas formas diferindo na resistência da fibra, e reconheciam, pelo menos, vinte formas distintas.

Atkinson (2) afirma que a rigidez das fôlhas, embora certamente influenciada pelo número de feixes fibrosos, também depende muito da espessura da lâmina foliar, outro caráter bastante variável. 
Esse autor cita que, segundo Hector, a planta de Phormium é bastante variável, mas que nenhuma tentativa foi feita para descrever as variedades. cientìficamente, razão por que existe grande confusão na nomenclatura.

Citando Cheeseman, Atkinson ainda relata que, considerando a importância econômica da planta, é bastante singular que não tenham sido feitas tentativas sistemáticas para reunir e cultivar, lado a lado, tôdas as: variedades existentes. E até que isto seja feito, é pràticamente impossívol descrevê-las cientîficamente ou aquilatar do seu valor.

Cross (3), ao estudar as várias formas com o objetivo de as reunir em grupos, logo deparou com uma extraordinária continuidade na variação. A espécie $P$. tenax foi por êle dividida em cinco grupos, cada um compreendendo diversas variedades, num total de 25. O seu trabalho também inclui uma descrição do conteúdo de fibra dessas variedades, assim como medições do diâmetro das fibras.

Farrel (4) afirma que as diferenças de coloração das fôlhas é considerada por alguns como o melhor meio de identificação das variedades. Afirma. ainda, que embora existam diversas variedades de Phormium, apenas três são clistinguidas pelo leigo : a variedade comumente denominada de "linho dos pântanos", de fôlhas comparativamente largas e dobradas ; a variedade das "colinas", de fôlhas estreitas e eretas ; e, finalmente, a variedade "variegada", utilizada como planta ornamental. Para o botânico, entretanto, são evidentes muitas pequenas variações, cuja influência sôbre a fibra é reconhecida pelos desfibradores e fabricantes de cordas.

Smerle (5) relata que separou 70 variedades de fórmio, tendo classificado, segundo scus caracteres, cêrca de 25. Cita também as percentagens de fibras em 23 variedades estudadas, tendo concluído que elas variam com. as formas distintas, porém são, em geral, sempre superiores a $10 \%$, salvo em variedades excepcionais, muito pobres, que sòmente contêm $5 \%$. Para as duas melhores variedades encontrou 22,0 e $22,4 \%$ de fibra.

Segundo Yates (6), supze-se que muitas das variedades sejam híbridcs: das duas espécies do gênero. As suas conclusões gerajs são as seguintes: a) Será possível cruzar com sucesso qualquer das duas variededes florescendo na mesma época ; b) as variedades, em geral, segregam quando são propagadas por sementes ; c) no futuro, as plantações serão feitas principalmente com híbridos oriundos do cruzamento de rariedades apropriadas.

Verifica-se, portanto, que, apesar da reconhecida existência do polimortismo no $P$. tenax, até agora nenhuma tentativa se fêz para estudar comparativamente o valor agrícola e tecnológico das diferentes formas (variedades?) existentes, mesmo na sua pátria de origem, a Nova Zelândia.

$O$ presente trabalho tem, pois, por finalidade apresentar os resultados preliminares sôbre o valor agrícola e industrial das diversas rariedades rultivadas no Estado de São Paulo, resultados êsses que reputamos de máxima importância para a orientação geral dos futuros trabalhos com exsiz planta. 


\section{II - MATERIAL F METODOS ANALÍTICOS}

\section{a) Material}

Em nosso meio, o $P$. tenax é comumente empregado como planta ornamental, nos jardins públicos e particulares, e como planta fornecedora de amarrilhos para enxertos, nos viveiros de mudas frutícolas. Como planta fibrosa, está sendo atualmente explorado em duas extensas culturas, localizadas nos municípios de Cabreúva e Pilar, estando em formação mais duas outras culturas, em Salesópolis e Jardinópolis.

Em Cabreúva, a cultura é feita apenas com a variedade localmente denominada bronzeada, a qual apresenta grande variabilidade, que, até certo ponto, pode ser explicada pela origem do material, obtido de diversos jardins e parques da cidade de São Paulo.

Em Pilar, cultivam as variedades espadana ou açoriana, originária de sementes introduzidas dos Açores; a bronzeada, bem uniforme e a ereta, cujo cultivo está sendo abandonado. Da plantação de espadana foram separadas duas formas distintas no hábito de crescimento, as quais foram denominadas de espadana de fôlhas eretas e espadana de fôlhas dobradas, sendo esta ultima a forma mais frequente na cultura.

As variedades gigante, gigabrom e ereta foram gentilmente cedidas pelo sr. José Paulos, que pussuia uma plantação no município de Pilar.

Para o presente estudo recorremos à coleção de variedades estabelecida na Estação Experimental de Jundiaí, pela Secção de Plantas Fibrosas Diversas. Essa coleção foi instalada, naquele local, em 17 de junho de 1944, utilizando-se o espaçamento de 1 metro entre as plantas.

Este trabalho baseia-se, portanto, no estudo das seguintes variedades: bronzeada, gigabrom, ereta, gigante, espadana de fôlhas eretas e espadana de fôlhas dobradas.

\section{b) Métodos analíticos}

Afim de verificar o valor tecnológico das diversas variedades em estudo, foram feitas, em amostras de fibra das fôlhas da primeira colheita, tôdas as determinações físico-químicas usualmente empregadas nos laboratórios para exame de fibras téxteis.

Damos, a seguir, um resumo dos processos de análise adotados, juntamente com algumas indicações sôbre o modo de interpretar os resultados.

\section{1) Análises físicas}

Comprimento médio. Esta determinação representa a média da medição direta de 600 fibras, em uma escala comum.

Largura média. Representa a média da medição direta de 200 fibras com auxílio de um microscópio munido de uma ocular micrométrica. 
Relação Y. Corresponde ao quociente da divisão do comprimento médio pela largura média das fibras. Quanto maior esta relação, tanto maior o valor industrial da fibra.

Pêso médio de 10 centímetros de fibra. Representa o pêso, em ambiente controlado, de 400 fibras cortadas a um comprimento fixo de 10 centímetros. Quanto maior êste valor, tanto maior o valor industrial da fibra, visto que êle nada mais é que o indice de finesa da fibra.

Resistência média à distensão. Esta determinação foi obtida no dinamômetro "Goodbrand", modêlo P-1, pertencente ao Instituto de Pesquisas Tecnológicas de São Paulo, empregando-se 600 fibras em estado natural para cada variedade.

Relação Z. Representa o quocicnte da divisão da resistência média à distensão pelo pêso médio de 10 centímetros de fibra. Quanto maior êste valor, tanto maior o valor industrial da fibra.

Elasticidade. Este valor é obtido conjuntamente com a determinação da resistência à distensão, no dinamômetro "Goodbrand", e representa o alongamento que a fibra sofre antes de arrebentar.

Resistência média à torção. As determinações foram feitas em um contador de torções de "Louis Schopper", usando-se uma amostra de 200 fibras para cada variedade. Esta caraterística, indicada pelo número de voltas ou pelo encurtamento em milímetros necessário para arrebentar a fibra, representa o índice de torcionamento que a fibra pode sofrer durante a fiação.

Higroscopicidade. Representa, em percentagem, a umidade perdida pela fibra quando sêca a $100-110^{\circ} \mathrm{C}$, até pêso constante. Quanto menor êste valor, tanto menor o ataque da fibra pelos agentes hidrolíticos.

Reabsorção. Representa, em percentagem, a umidade adquirida pela fibra após secagem a $100-110^{\circ} \mathrm{C}$.

\section{2) Análises químicas}

Todos os resultados referentes às análises químicas correspondem à média de duas determinações e são expressos na substância sêca a 100$110^{\circ} \mathrm{C}$.

Cinzas. Foi obtida por incineração em forno elétrico de um feixe de fibras com pêso inicial de 2 gramas. Uma percentagem elevada de cinzas, indica, geralmente, a presença de impurezas minerais.

Hidrólises. As amostras de fibra foram tratadas por uma solução de soda cáustica a $1 \%$, sob fervura, durante 5 minutos (hidrólise alfa) e durante 1 hora (hidrólise beta). Na hidrólise alfa, a perda de pêso da fibra indica a quantidade de substância removida pela ação solvente do alcali, ao passo que, na hidrólise beta, a perda de pêso inclui também aquela solubilizada pela ação "degradante" do alcali. A diferença entre os valores das 
duas hidrólises indica a suscetibilidade da fibra ao ataque por alcalis cáusticos diluídos e a quente.

Mercerização. Representa a perda de pêso que sofre a fibra quando tratada diurante 1 hora, a frio, por uma solução de potassa cáustica a $33 \%$. O valor obtido indica a capacidade da fibra de resistir à ação "degradante" do alcali.

Purificacão ácida. Representa a perda de pêso que sofre a fibra quando fervida em uma solução de ácjo acético a $20 \%$, durante 15 minutos, e depois lavada com álcool e água. A perda de pêso deve-se, principalmente, à remoção de impurezas casuais.

Nitração. Representa o aumento de pêso que sofre a fibra quando tratada durante 1 hora, a frio, por uma mistura de ácido nítrico e sulfúrico, em partes iguais.

Celulose. Para esta determinação empregou-se o método de Cross e Bevam, conforme indicação de Zemplén (7).

A percentagem de celulose em uma fibra é, sem dúvida, a base mais importante para o julgamento do seu valor intrínseco.

\section{III - OBSERVAÇÕES PRELIMINARES SÔBRE O COMPORTA- MENTO DAS VARIEDADES}

\section{a) Desenvolvimento.}

No primeiro ano após o plantio das variedades, o afilhamento das touceiras não permitia ainda executar o seu desdobramento, porém no segundo ano, em 1946, as diversas variedades se apresentavam em condições de fornecer uma quantidade razoável de mudas.

Inserimos no quadro 1 os dados referentes ao afilhamento (leques) médio das touceiras, para as diversas variedades e em diferentes períodos, os quais indicam a sua capacidade de reprodução vegetativa, caraterística esta que influi decisivamente sôbre a produçâo.

QUADRO 1

\begin{tabular}{|c|c|c|c|c|}
\hline$V A R I E A D E S$ & $26-10-45$ & $26-7-46$ & $3-3-47$ & $21-8-47$ \\
\hline $\begin{array}{l}\text { Bronzeada } \ldots \ldots \ldots \ldots \ldots \ldots \ldots \ldots \ldots \\
\text { Gigabrom } \ldots \ldots \ldots \ldots \ldots \ldots \ldots \ldots \ldots \\
\text { Ereta } \ldots \ldots \ldots \ldots \ldots \ldots \ldots \\
\text { Gigante } \ldots \ldots \ldots \ldots \ldots \ldots \ldots \\
\text { Espadana de fôlhas dobradas } \ldots \ldots \ldots \\
\text { Espadana de fôlhas eretas } \ldots \ldots \ldots \ldots\end{array}$ & $\begin{array}{r}8.8 \\
16.9 \\
13.4 \\
12.9 \\
5.1 \\
5.5\end{array}$ & $\begin{array}{l}20.2 \\
27.4 \\
30.0 \\
27.0 \\
18.8 \\
17.7\end{array}$ & $\begin{array}{l}22.5 \\
28.8 \\
30.2 \\
25.8 \\
17.3 \\
18.4\end{array}$ & $\begin{array}{l}24.9 \\
31.6 \\
32.1 \\
29.3 \\
21.3 \\
23.7\end{array}$ \\
\hline
\end{tabular}


$\mathrm{Na}$ quarta contagem dos leques, que coincidiu com a segunda colheita das fôlhas, a ordem das variedades, segundo a altura média das touceiras, era a seguinte :

\begin{tabular}{|c|c|}
\hline Variedades & $\begin{array}{c}\text { Altura } n \\
\text { (cm) }\end{array}$ \\
\hline Gigante $\ldots \ldots \ldots \ldots \ldots$ & 188 \\
\hline Espadana de fôlhas eretas & 180 \\
\hline Bronzeada $\ldots \ldots \ldots \ldots$ & 167 \\
\hline Espadana de fôlhas dobradas & 167 \\
\hline Ereta $\ldots \ldots \ldots$ & 162 \\
\hline Gigabrom... & 162 \\
\hline
\end{tabular}

A variedade ereta e a gigabrom apresentavam-se fortemente parasitadas por Crysomphalus sp.; quanto às demais, mostravam-se isentas dêsse parasita.

\section{b) Produção de fôlhas.}

Em 26 de agôsto de 1946 executou-se a primeira colheita das variedades, seguindo-se de outra executada um ano depois, obtendo-se as seguintes produções médias de fôlhas por touccira para as diversas variedades (quadro 2):

\section{QUADRO 2}

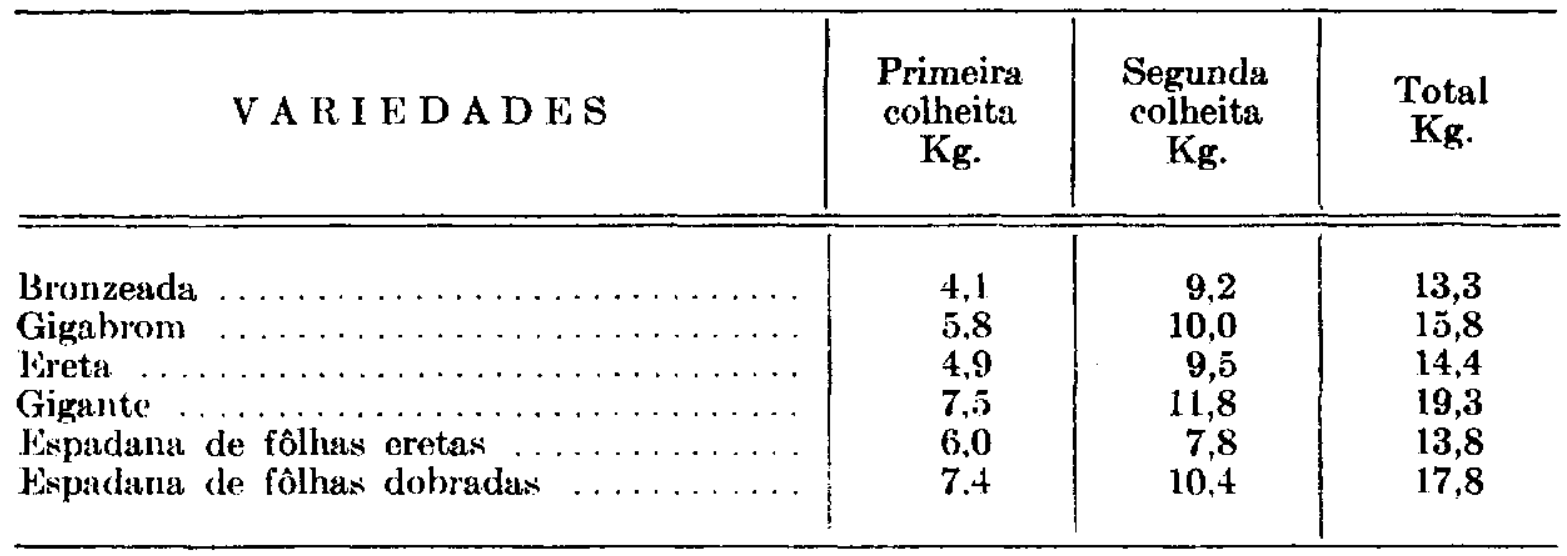

\section{c) Classificação das fôlhas.}

Antes do beneficiamento, tanto as fôlhas da primeira como da segunda colheita foram classificadas por ordem de comprimento, obtendo-se os dados inseridos nos quadros 3 e 4, respectivamente, que representam a distribuição percentual do pêso das fôlhas para cada classe de comprimento (em centímetros) e variedade.

Os dados do quadro 3 revelam que a variedade ereta, na primeira colheita, apresentava maior percentagem de fôlhas curtas, ao passo que as variedades espadanas e gigante não sòmente apresentavam percentagens razoáveis de fôlhas longas, como também menores percentagens de fôlhas curtas.

Os dados do quadro 4 mostram que, na segunda colheita, em virtude do desenvolvimento das plantas, os valores das classes de comprimento de 
fôlha tiveram que ser modificados. Nota-se, ainda, que nesta colheita, a variedade ereta apresentou novamente maior percentagem de fôlhas curtas, - que comercialmente é uma desvantagem, enquanto as espadanas e a gigante apresentavam ainda menores percentagens destas fôlhas. Apenas as variedades gigabrom e gigante apresentaram fôlhas de mais de 175 rentímetros de comprimento.

\section{QUADRO :3}

VAR I E D A D ES S

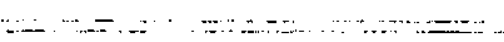

Brsmzeada

Gigabrom

Freta.

Giutunte.

Wpadana de follhas eretas

Fipadana de fôlhas dobradas

\begin{tabular}{|c|c|c|c|c|}
\hline $\begin{array}{l}160 \\
\cdot \mathrm{m}\end{array}$ & $\begin{array}{l}150 \\
1 \times m\end{array}$ & $\begin{array}{l}140 \\
\mathrm{~cm}\end{array}$ & $\begin{array}{l}130 \\
6 \mathrm{ml}\end{array}$ & $\begin{array}{l}100 \\
6 \mathrm{~m})\end{array}$ \\
\hline- & 29.3 & 23.9 & 28.7 & 18.1 \\
\hline - & 24.6 & 25.9 & 27.2 & 22.3 \\
\hline - & - & 18.5 & 38.8 & 42.7 \\
\hline 16.6 & 37.7 & 22.0 & 14.7 & 9.0 \\
\hline 21.2 & 30.0 & 28.0 & 15.0 & 3.8 \\
\hline & & & & \\
\hline
\end{tabular}

\section{QUADKO +}

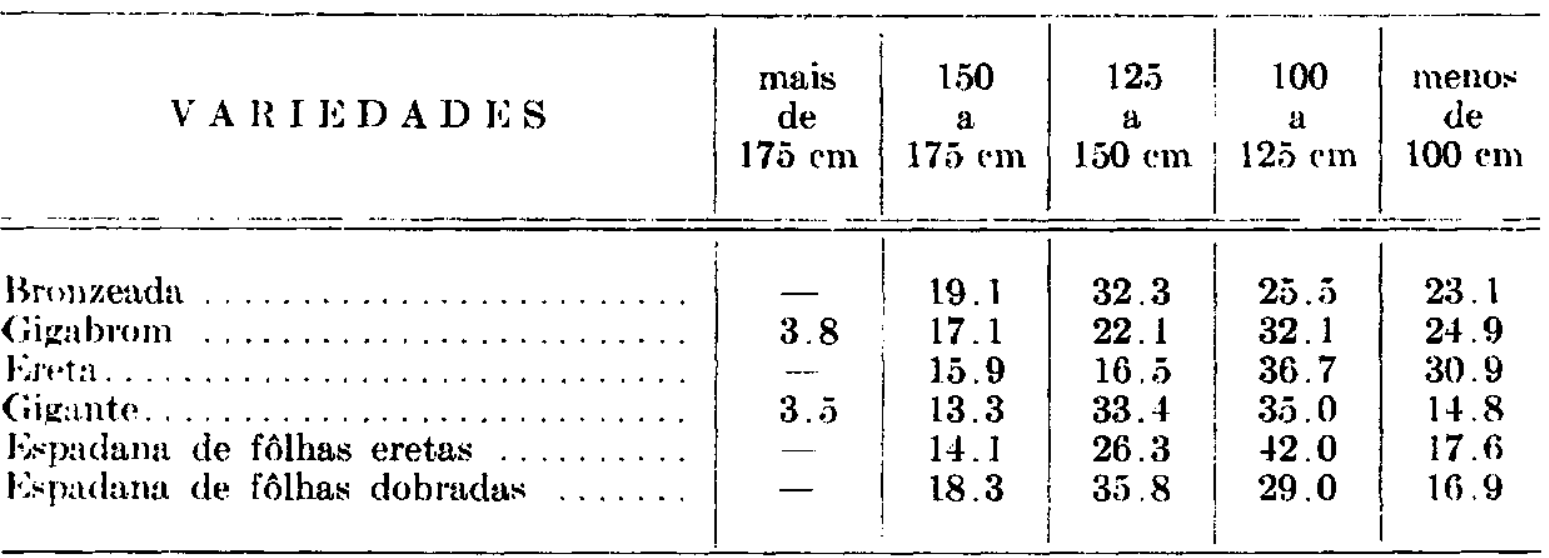

\section{d) Rendimento de fibra.}

Para uma opinião mais completa sôbre o valor dessas variedadś, exe-utou-se, na Fazenda Pinhal, em Cabreúva, o beneficiamento das fôlhas obtidas nas duas colheitas, em uma máquina de desfibragem fabricada na Nova Zelândia. As fôlhas da classe de um metro ou menos de comprimento foram passadas em uma máquina para desfibragem de fôlhas de abacaxi, adaptada para trabalhar com o fórmio, porém não foram elas computadas nos cálculos de rendimento de fibra apresentados no quadro 5.

A desfibragem foi feita separadamente, tanto para o material da primeira como da segunda colheita, para cada classe de comprimento de fôlha, dando-se à fibra obtida o tratamento usual, isto é, cortaram-se as pontas, lavou-se e secou-se ao sol.

No quadro 5 estão indicados os pesos das fôlhas, os pesos da fibra sêca obtida $c$ as percentagens de fibra, por variedade e colheita. 
QUADRO 5

\begin{tabular}{|c|c|c|c|c|c|c|}
\hline \multirow[b]{2}{*}{ VARIEDADES } & \multicolumn{3}{|c|}{ Primeiro corte } & \multicolumn{3}{|c|}{ Segundo corte } \\
\hline & $\begin{array}{l}\text { Pêse } \\
\text { das } \\
\text { fôlhas }\end{array}$ & $\begin{array}{l}\text { Pêso } \\
\text { da } \\
\text { fibra }\end{array}$ & $\begin{array}{l}\text { \%o de } \\
\text { fibrat }\end{array}$ & $\begin{array}{c}\text { Peso } \\
\text { das } \\
\text { fôlhas }\end{array}$ & $\begin{array}{c}\text { Pêso } \\
\text { da } \\
\text { fibra }\end{array}$ & $\begin{array}{l}\text { gir de. } \\
\text { fibrit }\end{array}$ \\
\hline Bronzeida & $\begin{array}{c}\mathrm{Kg} . \\
3250\end{array}$ & Kg. & $10 \mathrm{~s}$ & $\begin{array}{c}\text { Kig. } \\
70.800\end{array}$ & $\begin{array}{l}\text { Kg. } \\
9427\end{array}$ & 13.3 \\
\hline Gigabrom & 42,900 & 6,048 & 14.1 & 75,500 & 12,535 & 16.6 \\
\hline Ereta & 23,600 & 3,085 & 13,1 & 59,000 & 9,900 & $16 . \%$ \\
\hline Gigante & 44,600 & 4,656 & 10.4 & 70,400 & 9,887 & $1+.0$ \\
\hline Fipadana follhas eretas & 28,250 & 2,710 & 9.6 & 38,500 & 4,737 & 12.3 \\
\hline Fipadana fôllas dobradas & 40,950 & 3,311 & 8,1 & 62,500 & 7.723 & 12.3 \\
\hline
\end{tabular}

Pelos dados expostos no quadro 5, verifica-se que as variedades ereta e gigabrom, tanto na primeira como na segunda colheita, foram as que renderam maiores percentagens de fibra. Convém observar, entretanto, que a desfibradeira estava regulada para beneficiar a varicdade bronzeada, cultivada naquela fazenda, e que as únicas variedades que mostraram. necessidade de nova regulação na máquina foram justamente as espadanas. Como essa regulação não pudesse ser feita durante as desfibragens, houre um dilaceramento das fibras dessas variedades, perdendo-se no resíduo certa quantidade de fibra que não foi recuperada. As demais variedades comportaram-se satisfatòriamente no benefício, sendo que a variedade gigante foi a que apresentou melhor desfibragem.

\section{IV - RESULTADOS ANALÍTICOS E DISCUSSÃO}

Nos quadros 6 e 8 estão indicados os resultados médios obtidos nos exames físicos e químicos das fibras das diversas variedades estudadas.

\section{QUADRO 6}

\begin{tabular}{|c|c|c|c|c|c|c|}
\hline DETERMINAÇÃO & $\begin{array}{l}\text { Bron- } \\
\text { zeada }\end{array}$ & $\begin{array}{l}\text { Giga- } \\
\text { brom }\end{array}$ & Ereta & Gigante & $\begin{array}{c}\text { Espadana } \\
\text { f. e. }\end{array}$ & $\begin{array}{l}\text { Fospadana } \\
\text { f. d. }\end{array}$ \\
\hline 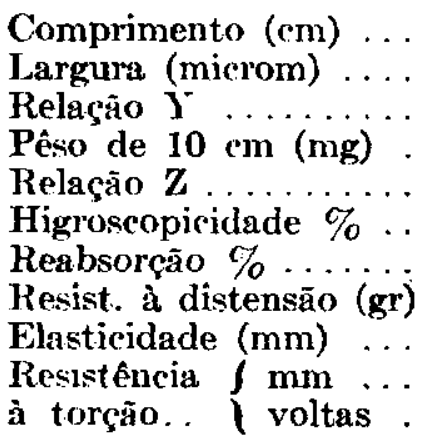 & $\begin{array}{c}92 \\
208 \\
4.279 \\
2.181 \\
48,05 \\
9,42 \\
10,40 \\
1.048 \\
1,4 \\
7 \\
82\end{array}$ & $\begin{array}{c}88 \\
192 \\
4.583 \\
3.072 \\
42,02 \\
9,30 \\
10,26 \\
1.297 \\
1,8 \\
8 \\
88\end{array}$ & $\begin{array}{c}83 \\
240 \\
3.375 \\
3.442 \\
39,10 \\
9,17 \\
10,09 \\
1.346 \\
1,7 \\
10 \\
95\end{array}$ & $\begin{array}{c}88 \\
216 \\
3.750 \\
3.357 \\
35,06 \\
9,12 \\
10,04 \\
1.177 \\
1,7 \\
8 \\
82\end{array}$ & \begin{tabular}{|c|}
90 \\
264 \\
2.879 \\
$\mathbf{3 . 4 3 6}$ \\
24,82 \\
9,42 \\
10,40 \\
853 \\
1,2 \\
7 \\
82
\end{tabular} & $\begin{array}{c}70 \\
256 \\
2.539 \\
3.781 \\
23,83 \\
9.13 \\
10.03 \\
901 \\
1,0 \\
4 \\
50\end{array}$ \\
\hline
\end{tabular}


Com rolação ar comprimento mélio da fibra das diferentes variedades, narla há a comentar, risto terem sido as fibras das variedades espadanas mejudicadas nis desfibragens, como já se esclareceu anteriormente.

Sôbre a largura média da fibra, obscrva-se que as espadanas e a ereta apreentaram as maiores dimensóes, ao passo que a bronzeada $c$ a gigabrom apresentaram as menores. A consequência disso pode ser melhor apreciada pelos dados da relaçăo $\mathrm{I}$. que significa que quanto mais elevados, tanto maior o valor téxtil da fibra. Teste particular, entretanto, as variedades espadanas foram prejudicadas pela desfibragem, porém, excluindo-se estas, verifiea-se que as variedades ereta gigante foram inferiores às rariedades bronzeada e gigabron.

Os resultados do pêso médio de 10 centímetros do fïbra revelam que itr espadanas e ereta são inferiores is demais ratriedales, principalmente om relação à bronzeada.

Os dados referentes à relação $Z$ indicam que existem diferenças entre as variedades, sendo que a bronzeada e gigabrom são superiores às demais, pois quanto maior esta relação, tanto maior o valor téxtil da fibra.

Quanto aos dados de resistência à distensão, a variedade ereta apresentou o valor médio mais elevado, scguindo-se, em ordem decrescente, as variedades gigabrom, gigante, bronzeada e espadanas. Como esta caraterística é a mais importante na determinação do valor téxtil de uma fihra, procurou-se analisar mais detalhadamente os dados obtidos para as diverwar variedades.

No quadro 7 estão indicadas as distribuiçós das frequências de resistência à dietonsão, em classes de 500 gramas, para as 600 fibras analisadas de cada rariedade.

\section{QLADRO :}

\begin{tabular}{|c|c|c|c|c|c|c|c|c|}
\hline VARISIAADH & $\begin{array}{c}0 \\
500 \\
50\end{array}$ & $\begin{array}{c}300 \\
\therefore \\
1000\end{array}$ & $\begin{array}{c}1000 \\
: 1 \\
1500\end{array}$ & $\begin{array}{c}1500 \\
: \\
2000\end{array}$ & $\begin{array}{c}2000 \\
a \\
2500\end{array}$ & $\begin{array}{c}2500 \\
a \\
3000\end{array}$ & $\begin{array}{c}3000 \\
\mathbf{a} \\
3500\end{array}$ & $\begin{array}{c}3500 \\
a \\
4000\end{array}$ \\
\hline Bronzend: & 49 & $25 t$ & 226 & 56 & 13 & 2 & _- & - \\
\hline Gigibrom & 38 & 176 & 201 & 113 & 51 & 15 & 5 & 1 \\
\hline Fret: & 42 & 188 & 165 & 120 & 50 & 21 & 9 & 5 \\
\hline (iigillits & 15 & 233 & 229 & 93 & 27 & 3 & 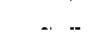 & \\
\hline Weptdant fôllat cret: & 135 & 304 & 120 & 31 & 8 & 1 & 1 & - \\
\hline Fopadanit follas dobrada & 120 & 214 & 117 & .5 & 11 & 2 & 1. & - \\
\hline
\end{tabular}

Os dados apresentados no quadro 7 revelam que, enquanto as espadanas e a bronzeada apresentavam um maior número de fibras fracas, as variedados gigabrom, ereta e gigante apresentavam um maior número de fibras fortes (e menor número de fibras fracas). 
Em relação aos dados sôbre reabsorção e higroscopicidade, as variedades não apresentaram diferenças sensíveis.

Entretanto, os dados referentes à elasticidade revelam que as variedades gigabrom, ereta e gigante são superiores às variedades bronzeada e espadanas, principalmente estas últimas. O mesmo acontece em relação aos dados sôbre a resistência à torção, tanto em encurtamento como em número de voltas.

No quadro 8 estão indicados os resultados obtidos nos exames químicos das fibras das diferentes variedades.

\section{QLADKO 8}

\begin{tabular}{|c|c|c|c|c|c|c|}
\hline$\underset{(\%)}{\operatorname{DHTER} \text { MINACOISS }}$ & $\begin{array}{l}\text { Bron- } \\
\text { zeada }\end{array}$ & $\begin{array}{l}\text { Giga- } \\
\text { brom }\end{array}$ & Freta & Gigante & $\begin{array}{l}\text { Lispadana } \\
\text { f. } \mathrm{e} .\end{array}$ & $\begin{array}{l}\text { Espadanil } \\
\quad \text { f. d. }\end{array}$ \\
\hline 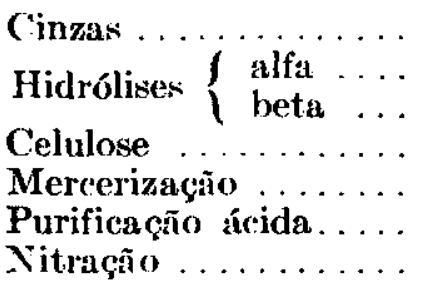 & $\begin{array}{r}1.08 \\
22,63 \\
23,45 \\
71,26 \\
22,25 \\
6,07 \\
131,75\end{array}$ & $\begin{array}{r}1,55 \\
19,93 \\
25,24 \\
70,60 \\
20,47 \\
6,22 \\
132,43\end{array}$ & $\begin{array}{r}1,66 \\
21,01 \\
26,04 \\
70,67 \\
25,08 \\
8,65 \\
133,99\end{array}$ & $\begin{array}{r}1,37 \\
21,97 \\
25,69 \\
69,28 \\
22,09 \\
\mathbf{5 , 7 4} \\
134,45\end{array}$ & $\begin{array}{r}1,15 \\
20,78 \\
30,11 \\
60,38 \\
21,08 \\
6,05 \\
123,77\end{array}$ & $\begin{array}{r}1,12 \\
24,07 \\
30,34 \\
59.89 \\
23,44 \\
5.52 \\
125,82\end{array}$ \\
\hline
\end{tabular}

Em relação ao teor em cinzas na fibra, as variedades não apresentaram diferenças sensíveis, o que já não acontece com referência às hidrólises alfa e beta, nas quais as maiores diferenças (hidrólise beta menos hidrólise alfa) ocorreram com as fibras das variedades espadanas e gigabrom. Neste particular, a fibra da variedade bronzeada revelou-se superior às demais, oferecendo maior resistência à ação "degradante" do alcali.

Sôbre as determinações de mercerização e purificação ácida, os dados revelam que a fibra da variedade ereta oferecia menor resistência à ação "degradante" do alcali e um maior conteúdo de impurezas casuais.

Quanto aos dados sôbre a celulose, substância básica que determina a qualidade da fibra, verifica-se que as variedades apresentaram diferenças sensíveis. Assim, enquanto a fibra da variedade bronzeada continha $71,26 \%$ de celulose, a fibra da variedade mais pobre, a espadana de fôlhas eretas, apresentava apenas $59,89 \%$.

Finalmente, em relação aos dados sôbre a nitração, olsserva-se que as espadanas apresentaram os resultados mais baixos, ao passo que para as outras variedades não houve diferenças sensíveis.

\section{SUMMARY}

In spite of the polymorphism of Phormium has long been known, no systematis: at tempt has been made until now to study comparatively the agricultural value and fiber quality of the varieties. 
This paper is concerned with preliminary results about leaf rield. fiber-rontent. and general growth of six varieties. of Phorminm tenax Forster induding a detailed fiber analysis.

It is concluded that the varieties have shown strong differences in plant development and fiber qualities, suggesting that some of them would be much morc suitable for the improvenent of existing areas, and the estahlishment of new ones on a com mereial basis.

\section{I.ITHEATU RA CITADA}

1. Illan, H. H. e V. D. Zotow. An artificial rosos between Phormium (olensoi and P. tenax. The X. Z. Jour. Sr. \& Teanol. $18: 799-804.1937$.

2. Itkinson, f.. H. Phornium tenax. The Now Zealand fibre industry. New Zealand Depart. Agric., Wellington. Bull. 95. pg. 1-5̃.5. 1922.

3. Cross, H. 1). Investigations on Phormium. Trans. X. Zeal. Inst. 56: 61-b6. 1913.

4. Farrell, J. New Zealand flax (Phormium tenax). Propagation, rultivation. and milling treatmont. Jour. 1)ept. Agric.. Victoria. 18: 6is8-671. 70n-706, 1920.

5. Smerle, (;. Improvement of Phormium tenax for the fibre industry. $x$. Zeal. Jour. Agric. 36 : 363-370. 1928.

6. Yates, J. S. Improvement of Phormium tenax. Resourch on breeding and rultivation of the plant. X. Z. Jour. Agrie. $36:$ 112-113. 1928.

7. Zemplän, (;. e F. F. Nord. Em Abderhalden Handbuch der Biologischen Arbeit:methoden. Abt. 1, 'Teil s: pr. 1-1101. 1922. 